\title{
NOTES ON THE MSS OF COSMAS INDICOPLEUSTES.
}

ThE Christian Topography of Cosmas, though carelessly edited by Montfaucon from a single inferior MS, is preserved in three fairly complete MSS.

$V=V a t . G r .699$, an uncial MS of the eighth or ninth century, contains only ten books, not eleven as Montfaucon states; and the ending of the tenth is different to that of $L, S$, and the edition. The beginning of the work too is different; f. $\mathbf{I}^{\mathbf{r}}$ contains a summary of contents much like $M^{1}$ p. 49, except that it ends with the title of Book X;

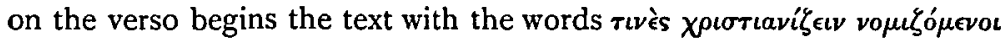
under the title $\dot{i} \pi \dot{\theta} \theta \epsilon \sigma r s$. The introductory prayer, the first prologue, and part of the second prologue, are omitted. There are several gaps due to the loss of leaves.

$L=$ Laur. Plut. ix 28 (s. xi) is the MS which Montfaucon copied for his edition, using $\mathrm{V}$ on three occasions to fill a gap. But in each

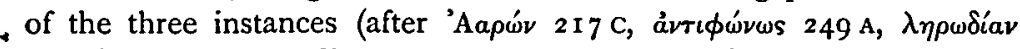
$405 \mathrm{C}$ ), with extraordinary carelessness he only inserted part of the

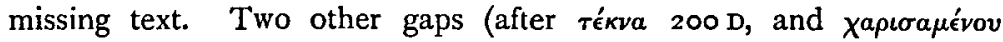
$393 \mathrm{C}$ ) which may be filled from $\mathrm{V}$ or $\mathrm{S}$ passed unnoticed. $\mathrm{L}$ has been corrected throughout by a later hand; and in such cases the first hand almost always agreed with $\mathrm{V}$ and $\mathrm{S}$.

$S=$ Sinai I 186 (s. xi) contains twelve books, like L, to which it is closely akin ; but the end of the twelfth book is deficient as in L. The beginning differs both from $L$ and $V$. On $f . I$ is the prologue; on

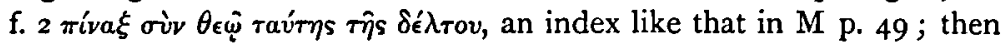

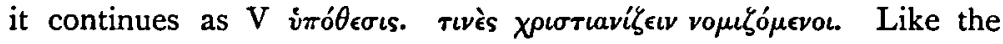
others it has several gaps.

The other fragmentary MSS at Vienna and Smyma, and the biblical MSS which use sections of the fifth book as catenae, add nothing of any value, and may be neglected.

In this short description of the MSS there are several points which call for special notice.

(I) $\mathrm{L}$ and $\mathrm{S}$ contain twelve books, $\mathrm{V}$ only $\mathrm{ro}$.

' $\because$ (2) The end of Book $\mathrm{X}$ is different in V and LS.

(3) All three MSS begin differently.

To these may be added a fourth equally important point, that $\mathrm{V}$ has the paragraphs on the Prophets in Book V in the Septuagint order, whereas $L$ and $S$ have the minor Prophets in the order of the Vulgate, the Major being inserted among them in a more or less chronological position. I have endeavoured to shew elsewhere ${ }^{2}$ that $\mathrm{V}$ indubitably

1 The references are to Migne Patr. Gr. 88.

J.T.S. Oct. 1906. 
preserves the correct order, and that the change in $\mathrm{L}$ and $\mathrm{S}$ is due to some later editor. That in itself, combined with the incongruity of an entire book devoted to Ceylon and its beasts and birds in an argument about the squareness of the world, is sufficient to cast suspicion on the two additional books found in L and S. Fortunately the hitherto uncollated MS S verifies that suspicion by openly confessing in the summary of contents that the eleventh book is $\ddot{\epsilon} \xi \omega \theta \epsilon \nu \tau \hat{\eta} s \beta i \beta \lambda o v$, while

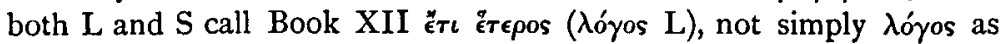
the other books. One would be sorry, however, to rob Cosmas of the honour of the book on Ceylon, and indeed to my mind it bears too obviously the stamp of Cosmas's methods and personality for its authenticity to be seriously questioned. The most probable explanation is that after Cosmas's death some one acting as his literary executor re-edited the Topography, adding two other books from Cosmas's papers, and making, for reasons best known to himself, the transposition already mentioned. Of this later edition $L$ and $S$ are apparently copies, while $\mathrm{V}$ is a less pretentious but more faithful copy of the original simple text.

Whether the editor who was responsible for that transposition and the addition of the two books had the boldness to add anything to the text on his own account is, perhaps, more doubtful : but there are several passages where it seems the most reasonable explanation. For example,

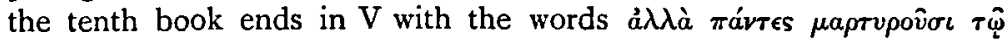

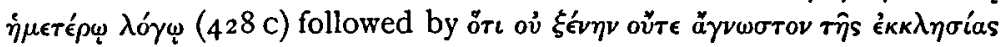

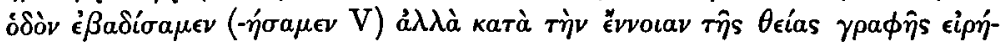

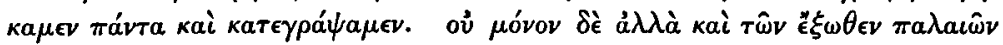

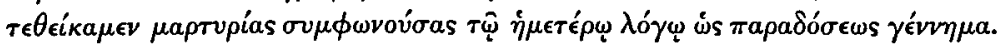

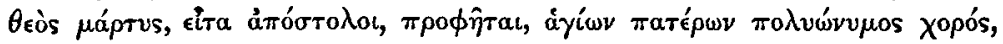

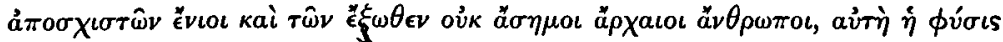

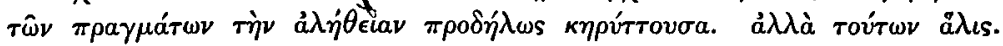

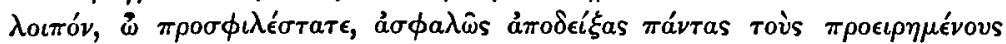

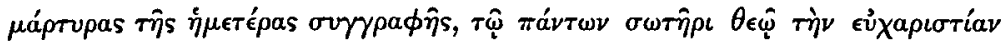

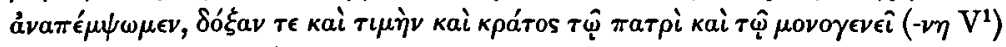

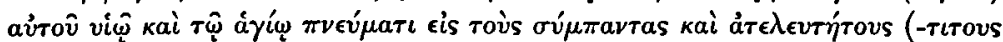
$\left.\mathrm{V}^{1}\right)$ a $i \hat{\omega} \nu$ as $\tau \hat{\omega} \nu$ ai ${ }^{\prime} \nu \omega \nu$. $\mathfrak{a} \mu \eta^{\prime} v$. Part of this is similar to the end of the book as it is found in L and S (M p. 428) but fuller; and with the preceding paragraph it forms a perfectly reasonable ending. If the quotations from the Fathers which follow in M pp. 428-44I actually existed in Cosmas's copy, there seems no conceivable explanation for their omission in V-it could hardly be due to loss of leaves in archetype, as the passage runs consecutively : but on the other hand there is every reason for their insertion by an editor who thought that he was thereby strengthening the argument.

It is possible that we find instances of his knowledge of patristic 
literature in other places, though the instances are not very certain.

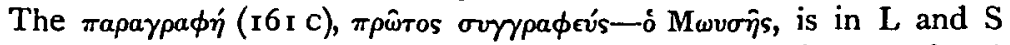

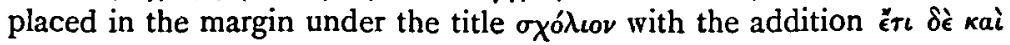

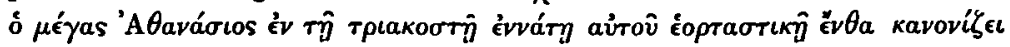

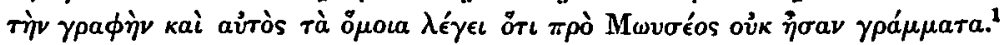

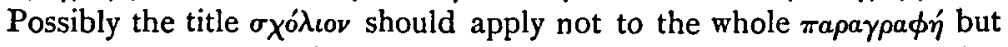
to the latter part, which was a subsequent addition. It is noticeable that in the section on the Catholic Epistles (372 D) the reference to

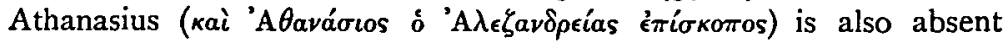
from V. Probably we should add to the same editor's sins of commission the addition of the paragraphs on Zachariah, Elizabeth, Mary, Anna, Simeon, and Christ $(277 \mathrm{c}-280 \mathrm{c})$.

There is a puzzling passage at the end of the eighth and beginning of the ninth book which may also be due to his meddling; but I am not at all sure of the true explanation. One thing is certain, that after

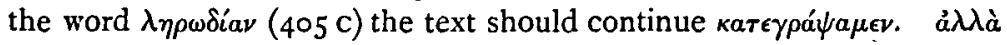

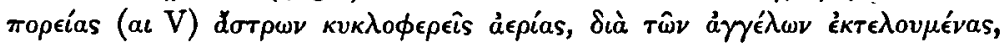

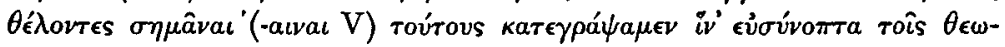

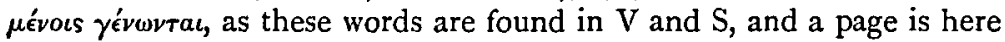
missing in L. That, however, is not the difficulty: it is the preceding passage which is in confusion in the MSS: V ends the eighth book

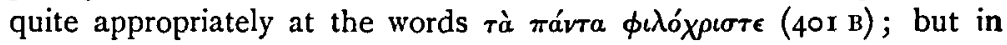
$\mathrm{L}$ and $\mathrm{S}$ there follows, as in the edition, a picture of the mountain round which Cosmas supposed the sun to make its nightly revolution, and a paragraph dealing with the subject of the next picture, with which Book IX begins. The picture is so out of place here that Montfaucon has thought it necessary to add a note accounting for its existence, and the paragraph is equally inappropriate as it refers in the past tense

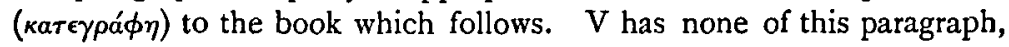
but fills the page after the end of Book VIII with a double picture of Hezekiah. Then follows the text of Book IX as far as $\dot{a} \mu \eta^{\prime} \nu$ (405 A).

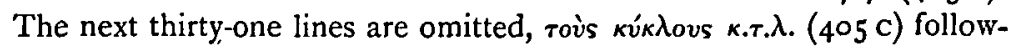
ing immediately after $\dot{\alpha} \mu \eta^{\prime} v$. After $\lambda \eta \rho \omega \delta i a v$ is the additional passage quoted above, and at the end of it a circular picture like that in $M$ p. 470 except that figures holding globes take the place of the fruits and herbs, while the centre is occupied by a mountain with the sun setting and rising around it (cf. Migne p. 402). In L and S Book IX begins , with a picture like that in Migne p. 470, followed by the text as in the edition, except that $\mathrm{S}$ still has the passage after $\lambda \eta p \omega \delta i a v$ and the picture precisely as $\mathrm{V}$; in $\mathrm{L}$ a page is missing.

I This phrase does not occur in the part of the $39^{\text {th }}$ letter which is preserved in .Greek, bnt it is found in the Coptic version published by Schmidt from a Pans MS.

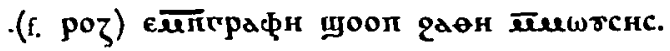

VOL. VIII.

R r 
- The debateable point is the picture and paragraph found in $L$ and $S$ at the end of Book VIII. There, as I have said, they are unnecessary and inappropriate; and though they would be appropriate enough in

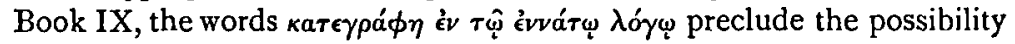
of its being a loose sheet escaped from that book. It is probable, then, that it is a later addition; and an examination of the pictures supplies a plausible reason for the addition. The picture in $\mathrm{V}$, which $\mathrm{I}$ have already described, is composed of two parts, a representation of the monthis and seasons and of the nightly revolutions of the sun. The, two additional pictures in $\mathrm{L}$ and $\mathrm{S}$ represent these two things separately, and that is probably the only reason for their existence and for the insertion of the explanatory paragraph.

The omission of kai ravitas to eipyáraro in $\mathrm{V}$ need not detain us : the passage is closely connected with the picture which follows, and as such passages are frequently compressed and written in a smaller hand to make room for the illustration, they are easily liable to omission as mere scholia. For the same reason they are occasionally omitted or transferred to the margin. For example, the short paragraph $\delta$ ou pavós

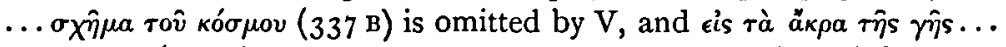
$\chi^{\hat{\omega}}$ pot $\delta$ v́o $(\mathrm{I} 84 \mathrm{~A})$ transposed to after $\pi \lambda \lambda_{\text {átos }} \tau o t o ́ v \delta \epsilon(185 \mathrm{~A})$ below a picture to which they are not applicable. On the contrary $\mathrm{V}$ preserves in the text, after an illustration between $188 \mathrm{D}$ and $189 \mathrm{~A}$, the words $\kappa a i$

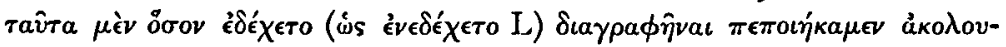

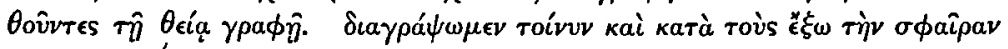

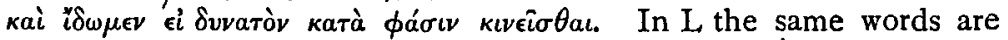
relegated to the margin as a scholium; while in $\mathrm{S}$ a page is missing.

Again, before a picture of the Tabernacle (212 D), both $\mathrm{V}$ and $\mathrm{S}$ have

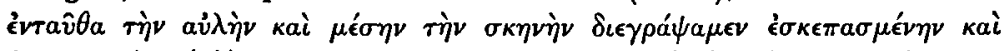

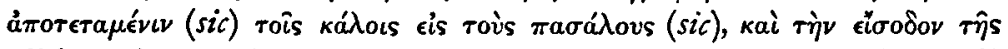

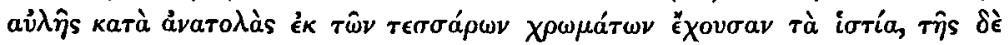

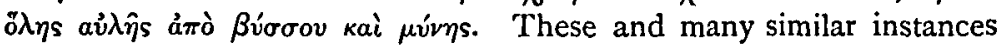
are due, no doubt, to the connexion of the paragraph with an illustration; but even when there is no picture in the case, the presence of the overwhelming number of notes, for which Cosmas himself apologizes $(57 \mathrm{~B})$, has naturally caused considerable confusion. The larger number of

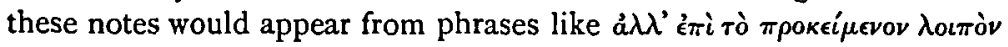

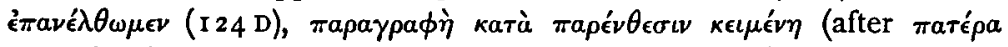

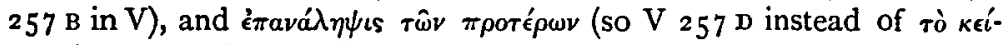
$\mu \in v o v)$ to have been written in the text, only marked off by the title

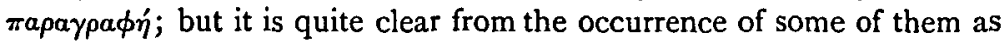

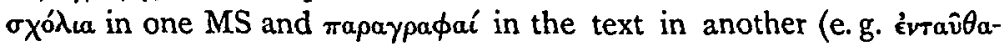
$\pi \rho \omega \tau o \nu . .$. rois $\ddot{e} \theta \nu \in \sigma u \nu \mathrm{I} 60 \mathrm{C}$ is in $\mathrm{L}$ and $\mathrm{S}$ a scholium, and so too is the

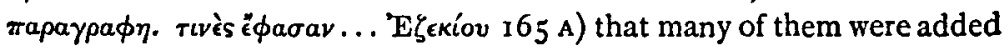


in the margin, even some of the longest, if we may draw such an

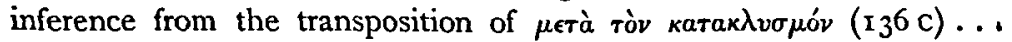

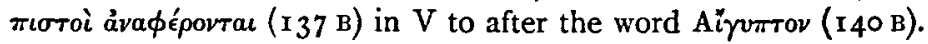

Naturally this system of marginal notes has led to the omission of many of them in one or more of the MSS ; for example, in the passage last referred to $\mathrm{V}$ omits the second short $\pi a \rho a \gamma \rho a \phi \eta \dot{~(137 ~ C) . ~ I n ~ s u c h ~}$ a text the collation of several MSS is absolutely necessary; and, as Montfaucon used only one, the other two, V and S, contributed a number of hitherto unprinted notes. At times, of course, it is difficult to determine whether they are genuine notes or mere scholia; but the probability is always in favour of their authenticity, ${ }^{1}$ as Cosmas was so profuse in adding notes as to leave little opening to any one else. Some of these additional passages are of considerable length, but for shortness' sake I will give only two.

Both $\mathrm{V}$ and $\mathrm{S}$ preserve at the end of Book V-the end, that is to say, of the original Topography-a passage which is lost in L. In S it is separated from the rest of the text by the heading EYXH in gold letters.

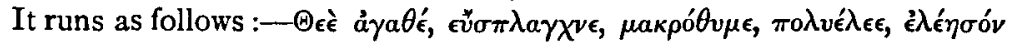

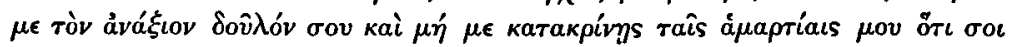

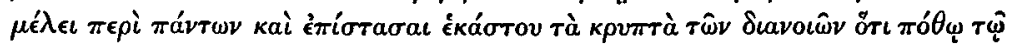

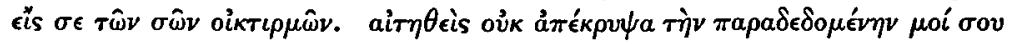

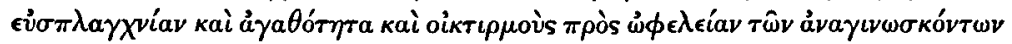

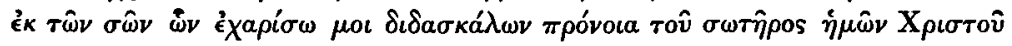

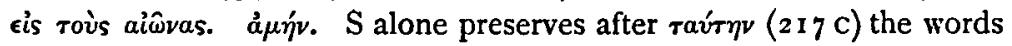

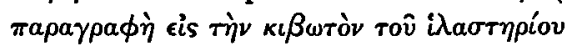

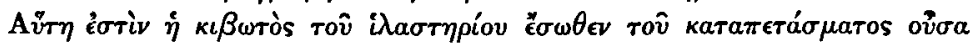

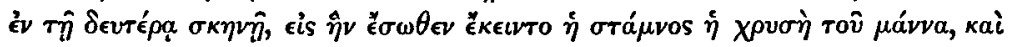

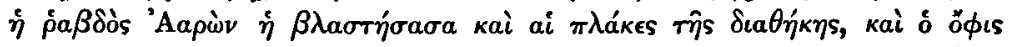

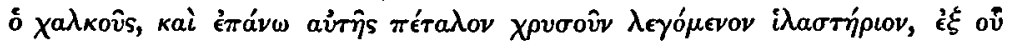

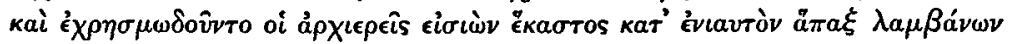

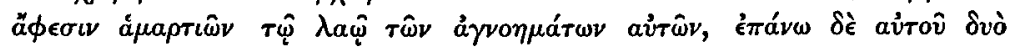

1 For example, a passage occurring actually within the rim of one of the illustrations of $L$ has every appearance of genuineness. Unfortunately $V$ and $S$ are both lacking for this passage at the end of the fourth book $\left(19^{2} \mathrm{~B}\right)$ in the open spaces of a picture like $M$ p. 465 no. $2:-$

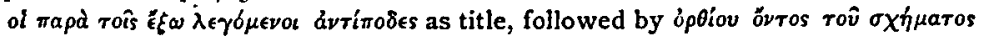

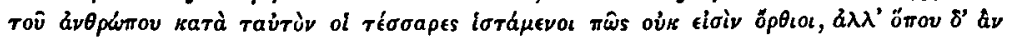

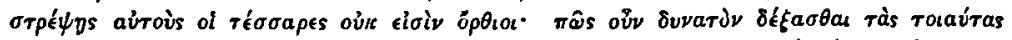

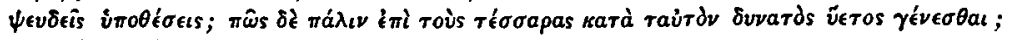

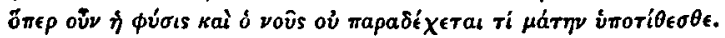

Several passages in Montfaucon's text are in a similar position : for example, $\mu a p r u p \in \hat{\epsilon} . . . \delta p \delta \mu o v(328 \mathrm{~A})$ is in V written on the left side of the picture, which is represented on the previous page of the edition; and the words which follow

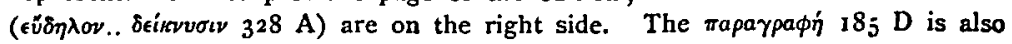
under a diagram, without any heading. 


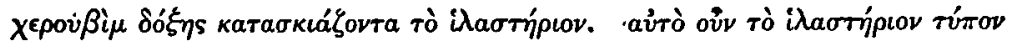

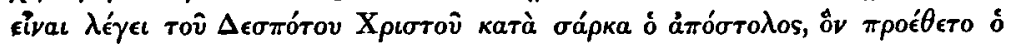

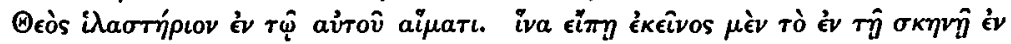

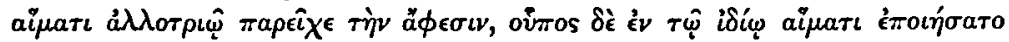

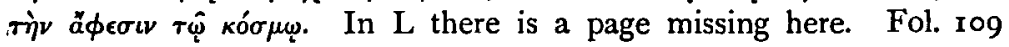
ends at 'Aapìv, f. I Io begins at out $\omega$ s oùv. We know from the other two MSS that a picture is also missing, but that picture and three and a half lines of text would not fill both sides of a page. So $\mathrm{L}$ must have had this paragraph too.

Such marginal additions were naturally liable to be inserted in the wrong place : and in that case $\mathrm{V}$ is invaluable, as belonging to a different edition to $\mathrm{L}$ and $\mathrm{S}$. It shews, for example, that $125 \mathrm{D}-128$ B the $\pi a p a-$

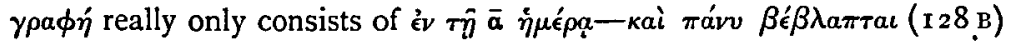

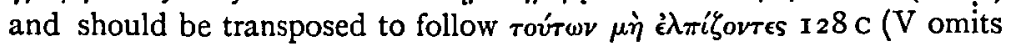

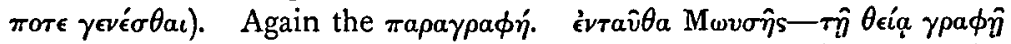
(205 C) should precede the passage entitled $\tau \dot{0} \kappa \epsilon i \mu \epsilon v o v(204 \mathrm{D}$ ), while

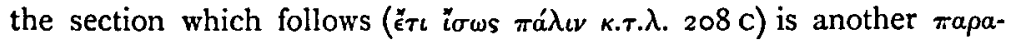
$\gamma p a \phi \eta^{\prime}$ so entitled in V. It may be noticed that here too there is an illustration in the case. Equally frequently the notes are not separated from the text. For instance V rightly marks a $\pi \alpha \rho a \gamma \rho a \phi \eta^{\prime}$ before $\Sigma \eta \mu \hat{a} v a \iota$

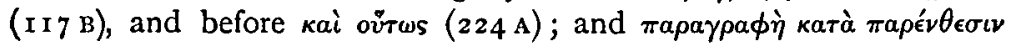

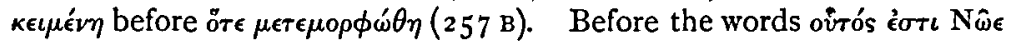
$\left(23^{2} \mathrm{C}\right)$ a division should be made, and the heading Nôt inserted. Such misdivisions are especially frequent in the case of small additional notes

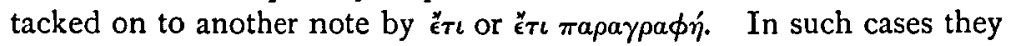
are invariably in red ink in $\mathrm{V}$, and should be given a separate line in an edition (e. g. at $204 \mathrm{~A}$, Il. 6 and 9, I89 B, 229 C, 232 B, $240 \mathrm{D}, 244$ D, \&C.).

A similar instance of transposition is the clause $\dot{\delta} \sigma \tau \eta^{\prime} \sigma a s, \epsilon i \pi \epsilon \nu-o \dot{v}$ duvaral $77 \mathrm{~B}$, which in the MSS precedes the quotation on which it is

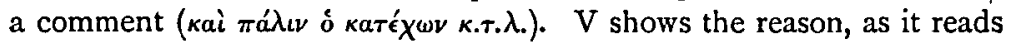

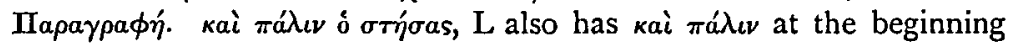
of both clauses.

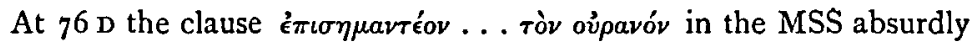
precedes the word 'Hoaias. Here $\mathrm{L}$ comes to the rescue with a marginal

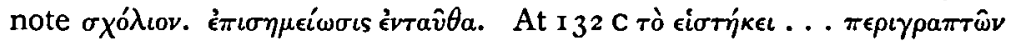

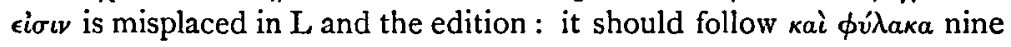
lines below as it does in V, reading rò oủv cir-. Though perhaps it can hardly be counted as a transposed note, $\mathrm{V}$ is undoubtedly right in transfer-

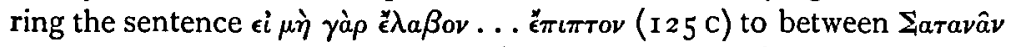

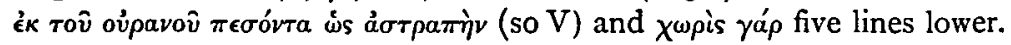

Again at $165 \mathrm{C}-\mathrm{D}$ in $\mathrm{V}$ the explanatory sentence ö $\pi \epsilon \rho$ каi тойтo...

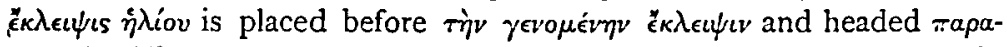

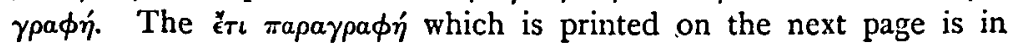


both $\mathrm{L}$ and $\mathrm{V}$ placed after ì $\Delta \epsilon \sigma \pi$ ó $\eta \mathbf{S} \mathrm{X}$ ptorós. Probably both notes were in the margin and should be printed together, the second being

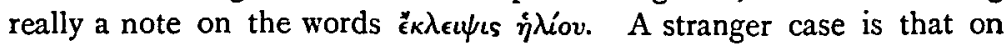

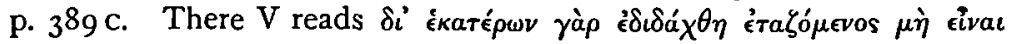

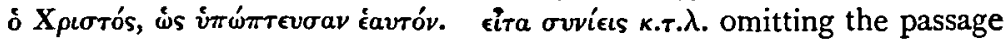

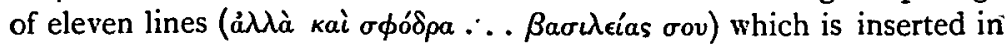

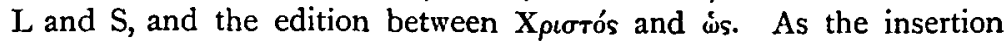
makes $\dot{\omega} s \dot{v} \pi \dot{\omega} \pi \tau \epsilon u \sigma a v$ éavróv untranslateable there is little doubt it is a marginal note wrongly inserted.

Now one might at first sight be inclined to imagine that this theory. of marginal additions supports Montfaucon's view that $L$ and $V$. represent two different recensions by the author. But, if one examines the instances more closely, I think one will find that they are rather opposed to than in favour of that theory; because on his assumption one would expect to find the additional passages in $\mathrm{L}$ and not in $\mathrm{V}$, whereas in fact there are just as many in $\mathrm{V}$ as in $\mathrm{L}$. Nor can they be assumed to be later additions in $\mathrm{V}$ because in cases where they appear in one MS in the text, in the other in the margin, it is almost invariably $\mathrm{V}$ which has them in the text and $\mathrm{L}$ in the margin. Still more conclusive evidence against it are the instances given above of marginal notes wrongly inserted by both MSS in the same place in the text, because they imply at least one common ancestor later than Cosmas's autograph copy for all the MSS. On the other hand all these objections fall to the ground if we assume $\mathrm{V}$ to be a tolerably careful copy of the work as left by Cosmas, $\mathrm{L}$ and $\mathrm{S}$ representatives of an edition made after his death.

There remains, however, a serious difficulty - that all three MSS begin the book in a different way. V's beginning is the simplest, an index

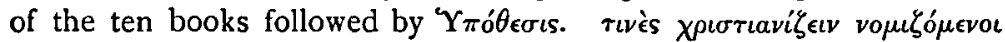

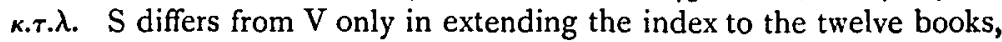
and in prefixing to it the first prologue, which is printed in Migne p. 53.

$\mathrm{L}$ omits the index and begins as the edition begins, with a prefatory prayer, a first prologue, and a second prologue. There is, however, one important variant from the text of the edition which I will notice later, taking the points in order: the introductory prayer preserved only in $\mathrm{L}$ need not detain us, as it is not of the smallest interest whether it is genuine or not; and it is just such a thing as might have been added by any monkish copyist. The genuineness of the first prologue I do not think any one will impugn, in spite of the fact that it is omitted by V. If in V's archetype as in $S$ it preceded the index, the leaf containing it may have well been torn off or become illegible or may simply have been overlooked. The real crux is the second prologue of $\mathrm{L}$, which ultimately joins with the $i \pi \delta^{\prime} \theta \in \sigma$ เs of the other MSS, though that 


\section{I4 THE JOURNAL OF THEOLOGICAL STUDIES}

title and the first few lines of the introters as it is found in the $\mathrm{V}$ and $\mathrm{S}$ do not exist in $\mathrm{L}$ at all : so that Montfaucon's reading is a composite reading made up from $L$ and $V$. L's reading is the same as the edition

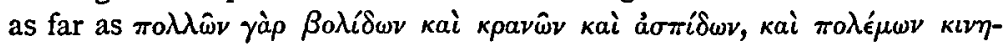

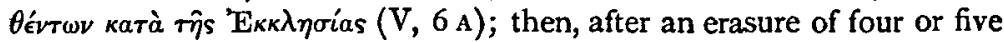

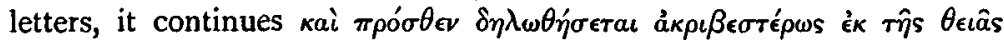

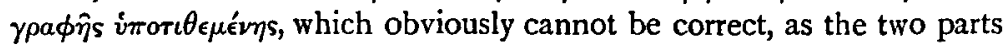
of the sentence do not fit at all. Montfaucon, finding the $i \pi 0^{\prime} \theta \epsilon \sigma i s$ of $\mathrm{V}$

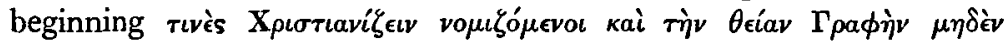

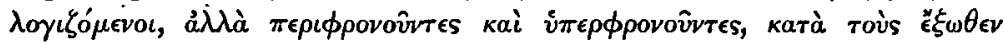

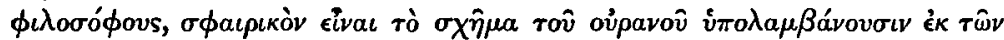

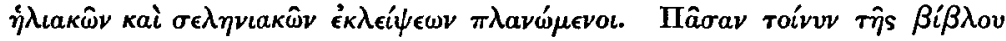

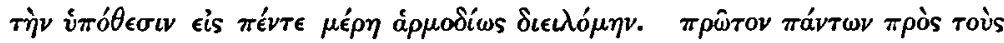

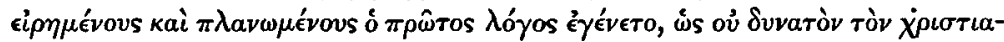

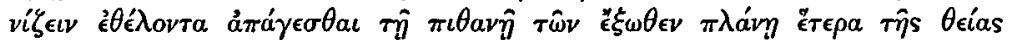

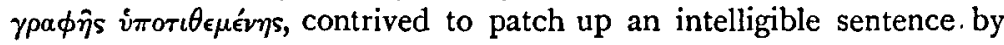
placing this immediately after $\dot{\epsilon}^{\prime} \kappa \kappa \eta \eta \sigma^{\prime} \alpha$ s and excising the words $\kappa a i$

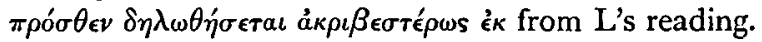

Now since $\mathrm{V}$ and $\mathrm{S}$, which, as $\mathrm{I}$ have shewn above, are representatives of the two different recensions here, for once agree in omitting that dedication to Pamphilus which forms the opening part of the second prologue in $\mathrm{L}$, one cannot help suspecting its genuineness, and the impossible manner in which it is made to join on to the $\dot{v} \pi \dot{\theta} \theta \in \sigma<s$ rather confirms one's suspicions. It may at first seem strange that, if we refuse to accept the present suspicious passage, the work is not formally dedicated to Pamphilus until the beginning of the second book; but if one reads more carefully one will find that that is quite appropriate. The first book is an address to all right-minded Christians, while in the second book he begins to deal with the subject which Pamphilus had

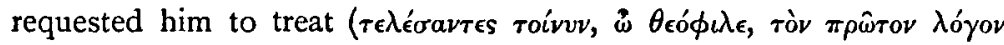
$\pi \epsilon \rho \grave{i} \tau \hat{\omega} \nu \pi \epsilon \pi \lambda \alpha \sigma \mu \epsilon{ }^{\prime} \nu \omega \nu$ X $\sigma \epsilon \omega s(73 \mathrm{D}))$. That being so I think there is little doubt that the beginning of the second prologue in $\mathrm{L}$ is due to a misconception on the part of some scribe or editor who thought a special dedication to Pamphilus was indispensable at the beginning of the work, and who therefore concocted one by paraphrasing the genuine dedication at the beginning of the second book. The difficulty is that one can hardly refer it to the same editor who transposed the prophets and added the last two books, because in that case it should be found in S as well as $\mathrm{L}$-unless indeed we assume that he added it in the margin, an assumption which would easily account for its omission by $\mathrm{S}$ and for the bungling manner in which it is inserted in $\mathrm{L}$.

E. O.'Winstedt. 